\title{
Pensar a África em sala de AULA: ENSINO, CONHECIMENTO LOGOPÁTICO E AFRICANIDADES NO FILME BEASTS OF NO NATION
}

\author{
To THINK Africa in THE Classroom EDUCATION, \\ LOGOPATHIC KNOWLEDGE AND AFRICANITIES IN THE FILM \\ BEASTS OF NO NATION
}

Humberto Perinelli Neto Doutor em História e Cultura Política. Professor da Universidade Estadual Paulista Júlio de Mesquita Filho. São José do Rio Preto, SP, Brasil perinellineto@yahoo.com.br

\begin{abstract}
Alexandre Cristiano Baldacin Junior
Graduado e Licenciado em Letras (Português/Espanhol) pelo Instituto de Biociências, Letras e Ciências Exatas (IBILCE/UNESP) de São José do Rio Preto, SP, Brasil alexandrecristianorg@gmail.com
\end{abstract}

Resumo: O texto apresenta análise do filme Beasts of no nation, segundo preocupação de gerar sua apropriação pedagógica para desenvolvimento de prática educativa envolvendo a Educaçáo para as Relaçóes Étnico-Raciais, mais especificamente o Ensino de História e Culturas Africanas. Trata-se de pesquisa com abordagem qualitativa, de natureza aplicada e que conciliou descrição e explicação, valendo-se para isso de investigaçóes bibliográficas e documentais. A interpretação promovida indica que Beasts of no nation é interessante para refletir sobre conceitos como etnia, nação, fronteiras, Estado e, a partir deles, compreender a realidade dos países africanos. Desta feita, a apropriaçáo pedagógica dessa obra fílmica é pertinente para a elaboração de propostas pedagógicas com base no pensamento decolonial e a interculturalidade.

Palavras-chave: Africanidades. Beasts of no Nation. Conhecimento logopático. Educação e cinema. Educação para as relaçóes étnico-raciais.

Aвstract: The text presents an analysis of the film Beasts of no nation to generate their pedagogical appropriation for the development of educational practice focused on the Education of Ethnic-Racial Relations, more specifically the Teaching of African History and Cultures. It is a research with qualitative approach, applied nature and that reconciled description and explanation, using bibliographic and documentary investigations. The interpretation promoted indicates that Bests of no nation is interesting to think about some concepts such as ethnicity, nation, borders, State and them, for understanding African countries. A pedagogical appropriation of this film is pertinent for the elaboration of pedagogical proposals based on decolonial thinking and interculturality.

Keywords: Africanities. Beasts of no Nation. Logopathic Knowledge. Education and cinema. Ethnic-racial relations education. 


\section{Introdução}

Em 2004 foram publicadas as Diretrizes para a Educação para as Relaçóes Étnico-Raciais e o Ensino de História e Cultura Africana e Afro-brasileira. As diretrizes reforçavam o principal objetivo da Lei I0.639/2003, a saber: promover açóes que visam combater o racismo e a discriminação em relação aos negros (pretos e pardos). Nesse documento, consta ainda que a educação para as relaçóes étnico-raciais poderá ser levada a cabo:

[...] em escolas devidamente instaladas e equipadas, orientados por professores qualificados para o ensino das diferentes áreas de conhecimentos; com formação para lidar com as tensas relaçóes produzidas pelo racismo e discriminaçôes, sensíveis e capazes de conduzir a reeducação das relaçôes entre diferentes grupos étnico-raciais [...]. (BRASIL, 2004, p. II, grifo nosso)

Nesse trecho das Diretrizes (2004), chama atenção o emprego do

I que sente; que tem sensibilidade

2 receptivo a impressóes sensórias Ex.: s. à dor

3 que recebe facilmente as impressóes ou sensaçōes externas

Ex.: narizs. a pequenas alteraçóes de aroma

4 capaz de sentir e captar o que existe e de expressá-lo

Ex.: um artistas.

5 de alguma importância; apreciável Ex.: houve uma quedas. nas vendas

6 que se comove facilmente, que se impressiona Ex.: não fale desse assunto com ela porque ela é muito s.

7 propenso a participar das dores alheias

8 emocionalmente favorável e compreensivo; solidário Ex.: demonstrou estar s. à nossa causa 
9 que facilmente se ofende ou se melindra

Io que indica a menor diferença ou alteração (diz-se de instrumento) (HOUAISS, 2009)

Diferenças à parte, notam-se proximidades entre as várias definiçôes em torno de 'sensível'. Elas remetem a vivência de conhecimento produzido entre o empírico e o estético e, por isso, capaz de conectar o sujeito à realidade (empírico), ao passo que também favorece a desnaturalização dessa realidade (estética), à medida que implica conhece-la sob nova perspectiva (sensorial, emocional). Além disso, elas sugerem mudança do estado daquele que é sensibilizado, pois ele passa a "captar", ser receptivo, "se comove", ser "compreensivo" e "solidário", "expressar" o que existe, se ofender/melindrar, bem como "participar das dores alheias".

Visto dessa maneira, o termo "sensíveis" parece bem empregado num documento envolvendo o negro no Brasil. Séculos de escravidão e de malsucedida inserção do negro na sociedade fizeram com que a cotidianização das violências praticadas contra essa parcela da população e a invisibilidade e o menosprezo contra o legado sócio-cultural de povos africanos fossem algo normal no Brasil. Superar esse estado de coisas implica promover a construção de discursos e práticas dotadas da capacidade de desnaturalizar, re/conhecer e promover mudança nas pessoas.

Cientes disso, promovemos pesquisa em que nos dedicamos a analisar o filme Beasts of no nation (2015), com a preocupação de gerar sua apropriação pedagógica para desenvolvimento de prática educativa envolvendo a Educação para as Relaçôes Étnico-Raciais, mais especificamente o Ensino de História e Culturas Africanas.

A pesquisa apresentou como fundamentação teórica Paulo Freire (20I6), posto que esse autor destacou a necessidade de a ação dos professores envolver materiais didáticos diversos, mobilização de vários conhecimentos, exercício da autonomia e de ser constituída a partir das necessidades pedagógicas reais.

O referencial teórico igualmente envolve contribuiçóes de Júlio Cabrera (2006), por refletir sobre a capacidade de o cinema propiciar a construçáo epistemológica/estética/política do conhecimento, assim como de identidades socioculturais e imaginários. 
A pesquisa proposta apresentou abordagem qualitativa, natureza aplicada e conciliou descrição e explicação, valendo-se para isso de investigaçóes bibliográficas e documentais. (GIL, I994; 2007; MINAYO, 2000; TRIVINOOS, I987; GAMBOA, I997; ALVES-MAZZOTTI, GEWANDSZNAJDER, I999)

\section{Cinema e Educação}

$\mathrm{O}$ cinema, enquanto linguagem, pode e merece um lugar à parte dentro das salas de aula, de modo que toda sua gramática e história sejam trabalhadas a partir de conceitos básicos de câmeras, cortes e montagens, chegando às técnicas do fazer cinema, como a edição, a mixagem de som etc. (PERINELLI NETO, 20I6). O cinema poderia ainda ser empregado como forma de complemento importantíssimo nas já tradicionais matérias escolares, como afirma Marcos Napolitano (2008, p. o8): "Não apenas todas as disciplinas tradicionais estão cobertas pelos filmes (algumas mais, outras menos), mas também todos os temas transversais e atividades especiais complementares."

Ademais, utilizar o cinema em sala de aula não seria apenas construtivo no âmbito do conhecimento da linguagem cinematográfica. Essa plataforma, por conta de seu efeito de ilusão de realidade, proporciona ao aluno um aprofundamento em algumas questóes que complementariam fortemente a sua imersão e compreensão do conteúdo. O filósofo argentino Julio Cabrera contribui com este pensamento ao propor a definição do "conceito-imagem", entendendo que envolve:

[...] experiência que é preciso ter, para que se possa entender e utilizar esse conceito. Por conseguinte, não se trata de um conceito externo, de referência exterior a algo, mas de uma linguagem instauradora que precisa passar por uma experiência para ser plenamente consolidada [...]. É claro que um filme pode ser colocado em palavras, no que se refere a seu componente puramente lógico. [...]. O que se acrescenta à leitura do comentário ou à sinopse no momento de ver o filme e de ter a experiência que o filme propóe (a experiência do que 
o filme é) não é apenas lazer, ou uma 'experiência estética', mas uma dimensão compreensiva do mundo. (CABRERA, 2006, p. 2I)

Desse modo, a experiência de ver filme se instaura a partir de questáo logopática, ou seja, conhecimento produzido pelo imbricamento entre razão e emoção, ambas geradas a partir do conceito-imagem. Para exemplificar com clareza esse ponto, Cabrera afirma que podemos tratar a questão da dúvida e da incerteza a partir de exposição teórica, mas, ao exibirmos Blow-up (I966), por exemplo, podemos levar a reflexão a outro patamar, uma vez que a experiência da incerteza apresentada nesse filme poderá potencializar a reflexão do aluno.

Agora, pensemos, conforme apresentado por Napolitano (2008), que o cinema é ótima forma de trabalhar temas transversais, devido ao fato de ser multifacetado. Quando nos deparamos com temas como as relaçóes étnico-raciais - que compete a diversas, senão todas, as áreas do saber, conforme apontam as DCNs -, temos uma questão propícia para se trabalhar com o cinema. Cabe lembrar que o cinema é uma mídia, desse modo, configura matriz cultural e socializadora. Decorre que, trabalhar questôes como as étnico-raciais a partir dessa perspectiva é de grande ganho para as práticas educativas críticas, uma vez que as africanidades compóem a cultura brasileira, da mesma forma que o cinema. Assim, trabalhá-las de maneira articulada é contextualizar o aluno duplamente em sua realidade nacional. Setton (2010, p. I3) afirma que: "[...] refletir sobre as mídias a partir do ponto de vista da educação é admiti-las enquanto produtoras de cultura."

Essa inserção do cinema na educação pode ser feita, dentre outras maneiras, por meio da mídia-educação, que segundo Belloni e Bévort (2009) é uma forma de apropriar-se crítica e criativamente da mídia que está ao redor de nós, a todo momento. Ademais, a mídia-educação prevê completa integração das mídias nos meios e nos processos educacionais, sendo condizente em todas suas instâncias: (i) o que elas transmitem, (ii) como transmitem (linguagem), além de sua (já usual) (iii) função de instrumento.

Outro exemplo da importância do cinema na formaçáo de jovens é a experiência feita por Alegria e Duarte (2008) em que vinte e cinco crianças (dos sete aos treze anos) foram entrevistadas quanto ao seu conhecimento 
de um grupo de filmes, selecionados previamente. Constataram que as crianças conheciam quase todos os oitenta filmes selecionados, entretanto, não conseguiam avaliar quais eram bons ou ruins, na verdade, afirmavam que todos eram bons. Esse fato apenas demonstra o quanto é necessário a reeducação do olhar, ou, como afirmam os autores, levar em conta o "princípio de que o cinema é uma das mais importantes artes visuais da atualidade, com um imenso poder de atração e indiscutível potencial criativo." (ALEGRIA; DUARTE, 2008, p. 73)

Contudo, o cenário que temos do cinema e das mídias dentro da sala de aula é táo caótico quanto o que se encontra fora dela. Muitas vezes ele é analisado apenas pelo tema, sem qualquer outro aspecto que compóe a arte cinematográfica - isso quando ele não é tratado apenas como recompensa ou entretenimento dentro de sala de aula. Ademais, as medidas institucionais para incluir o cinema nas aulas carregam consigo problemas, como os trazidos pela Lei I3.006/I4. Tal legislaçáo determina que "a exibição de filmes de produção nacional constituirá componente curricular complementar integrado à proposta pedagógica da escola, sendo sua exibição obrigatória, por, no mínimo, duas horas mensais." (BRASIL, 2014) Entretanto, deixa a resolver questôes como a formação docente e o fornecimento dos filmes.

Ao refletir sobre essa Lei, Fresquet (2015) apresenta outras três importantes noçóes acerca do cinema, que dialogam muito com o propósito da pesquisa envolvendo Beasts of no nation e africanidades proposta neste texto. A primeira crença diz respeito à "possibilidade que o cinema tem de tornar comum [...] o que não nos pertence” (FREQUEST, 2015, p. 07), promovendo até mesmo formas de viajar e habitar diferentes espaços-tempos.

A segunda crença vê o cinema como "forma de ver e estar no mundo que podem perturbar uma ordem dada, do que está instituído, dos lugares de poder" (FRESQUET, 20I5, p. o8), em outras palavras, uma forma de não alienação, de inquietação. Por fim, o cinema como "possibilidade de entrarem em contato com filmes, imagens, sons [...] que não são pautadas pela função social ou pela necessidade de fazer um mundo mais bonito.” (FRESQUET, 2015, p. 8)

Nesse sentido, se refletirmos sobre as Africanidades por meio da exibição de filmes de origem africana ou uma boa representação das Áfricas, 
podemos construir um momento extremamente proveitoso para o aluno, isto porque ele experimentaria uma realidade que, ao mesmo tempo, se aproxima e se afasta da sua: se aproxima pelo drama humano e a forte ligaçáo cultural; se distancia por ser outra realidade. E é nesse processo que os preconceitos, bem como a noção do Outro e, simultaneamente, de si, vão sendo constituídos.

Essa forma de emprego do cinema dialoga com Paulo Freire, estudioso que apresenta concepção de prática educativa progressista. Nas palavras de Freire (20I6, p. 34):

[...] uma das tarefas precípuas da prática educativo-progressista é exatamente o desenvolvimento da curiosidade crítica, insatisfeita, indócil, Curiosidade com que podemos nos defender de 'irracionalismos' decorrentes $d o$ ou produzidos por certos excessos de 'racionalidade' de nosso tempo altamente tecnologizado.

Desse modo, refletir sobre a prática educativo-crítica e sobre o papel do cinema implica pensar sobre o próprio processo de ensinar-aprender, visto que é um ato que envolve compromisso inerente com a sociedade. Negar a presença do cinema na escola é negar a realidade, já que as mídias e os superestímulos audiovisuais se fazem presentes na sociedade desde o século XIX. Ainda nas palavras de Freire (2016, p. 26), a prática educativocrítica constitui "[...] uma experiência total, divertida, política, ideológica, gnosiológica, pedagógica, estética e ética [...]”

\section{As representaçóes da África e o cinema africano}

É importante pensar a repercussão de filmes com temáticas africanas e originários da África nas mídias nacionais e internacionais, já que sempre houve grande descaso na abordagem desse continente em sala de aula. Entretanto, quando falamos de Brasil, a questão da desatenção ao continente africano é mais séria, visto que somos o segundo país com mais negros no mundo. Senger chama a atenção para essa questão da mídia: 
As coberturas de acontecimentos na África perdem em atenção se relacionadas a outras localidades, e muitas vezes questôes humanitárias que precisam desesperadamente de atenção da comunidade internacional não aparecem, ou ocupam diminuto espaço na agenda da grande mídia. Até mesmo nas representaçôes cinematográficas de África podemos ver a alusão a essa situação. (SENGER, 20I2, p. 529)

Além disso, continua Senger (20I2, p. 528), quando a mídia aborda esse continente, o faz de modo generalizado, já que "fala-se em África, mas não de seus países e suas especificidades de tal forma que se torna comum confundi-la com um país." Essa situação gera outro problema: o continente africano acaba não tendo voz diante do Ocidente. Pode-se dizer que essa percepção se deve àquilo que Said (2007, p. II5) chama de orientalismo, que ele descreve como "termo genérico que tenho empregado para descrever a abordagem ocidental do Oriente.” Em um caso como no outro as abordagens são pejorativas e preconceituosas.

O continente africano conta com Nollywood, a indústria cinematográfica nigeriana que, atualmente, se encontra como a segunda maior do mundo em número de títulos produzidos anualmente, ficando atrás forma de começar a entender a indústria de filmes nigerianos seria de relacioná-la com as novelas brasileiras" (UECHI, 20I5, p. oI), uma vez que tem um papel fundamental na sociedade nigeriana, assim como as novelas têm na brasileira. Porém, encontram-se barreiras invisíveis que não permitem: (i) a outros países africanos desenvolver, de forma satisfatória, uma indústria cinematográfica tal como a Nigéria; e (ii) que os filmes da própria Nollywood sejam verdadeiramente integrados ao cenário internacional, em festivais de ampla concorrência como Cannes, que chegou a ficar 13 anos sem representante africano.

Essas barreiras invisíveis se dão por vários fatores, dentre eles: (i) a forte intervenção europeia no cinema africano - principalmente da França - por meio de incentivos à produção cinematográfica, mas sempre impondo influências nas produçóes por conta do financiamento; (ii) a intervenção estatal na produção de filmes, que acaba gerando censura, como é o caso da Argélia; (iii) as distribuidoras estrangeiras que inun- 
dam o mercado africano com filmes hollywoodianos e bollywoodianos; (iv) a falta de cinemas por todo o continente. (ARMES, 2007). Essas questôes fazem com que não haja outros grandes centros produtores de cinema na África, bem como motiva Nollywood a produzir filmes que serão distribuídos em mídias físicas, para que sejam consumidos individualmente, nos domicílios, de modo que dificilmente cheguem ao mercado internacional. (BALOGUN, 2007). Juntando o descaso da mídia com o problema de produção e distribuição de filmes africanos, resta consumir o que Hollywood produz, tornando a indústria cultural norte-americana "o maior propagador de conhecimentos acerca de África.” (SENGER, 20I2, p. 530). Consumir o material hollywoodiano não seria problema, caso não fossem registrados: (i) o protagonismo branco presente na maioria das obras; (ii) a deturpada imagem dos africanos e da África; e (iii) a equivocada representação do que pensa/sente o africano sobre a África.

Entretanto, o filme norte americano Beasts of no nation (2015), adaptação de romance homônimo do escritor nigeriano Uzodinma Iweala, apresenta alguns aspectos interessantes. Acompanhamos nessa obra a história do jovem garoto Agu, que acabou sendo transformado em uma criança-soldado durante conflito militar que ocorreu em seu país. Passamos, então, a refletir sobre Beasts of no nation, enfatizando questóes como etnia, raça, fronteiras, nação e Estado.

\section{$4 \quad$ Fronteiras africanas}

Muitos dos principais conflitos que ocorrem na África contemporânea decorrerem de três noções: nação, etnia e fronteira. Não há, portanto, como trabalhar a apropriação pedagógica de filmes sobre a África pósindependência e deixar de lado, ou pouco aprofundar, essas problemáticas. A vivência dessas noçôes gera, até hoje, fortes conflitos no continente, caso do Sudão do Sul que só em 20 I I se tornou independente, mas que acabou, nesse processo, por travar uma guerra com o Sudão, situação que o transformou num país que nasceu pobre e em guerra.

O filme Beasts of no nation nos permite trabalhar essas temáticas, uma vez que dialoga com elas a partir do próprio título, que leva consi- 
go a ideia de feras que não possuem nação. A partir desse apontamento inicial, podemos questionar: $\mathrm{O}$ que é nação? Existem Estados-nação na África?

O filme também apresenta um drama vivido num país cujo nome nunca é mencionado, expediente narrativo que suscita reflexóes quanto a qual seria a representação e as questôes acerca de um país sem nome, ou se tal expediente tem a intenção de generalizar a trama de Beasts para todo o continente.

Por fim, tem-se a questão dos conflitos étnicos, que formam mais um ponto em que estão envolvidas tanto a problemática da criação de nação quanto a origem das guerras civis, sendo estas últimas o foco do filme.

Apresentados os três pontos, podemos refletir sobre a arbitrariedade do processo histórico de definição das fronteiras no continente africano. A origem de suas instáveis fronteiras está ligada ao processo de colonização europeia que se consagrou na Conferência de Berlim (I884-I885), que costuma ser tomado como o ponto de partida para a partilha da África, pois foi nela que se estabeleceram, pelas potências europeias, os limites territoriais do continente e seus respectivos proprietários, originando as atuais fronteiras dos 'países africanos'.

A arbitrariedade na definição das fronteiras pelos europeus na África será responsável por agrupar grupos étnicos inimigos, separar aliados e, por conseguinte, estruturar toda a base dos conflitos que configurariam boa parte dos embates no/do continente até os dias atuais. Isso se dá pelo fato das fronteiras imperialistas, que hoje dividem o continente em 54 países, não darem conta das mais de duas mil etnias africanas existentes antes da chegada dos invasores.

\section{Etnia e naçáo}

Uma vez estabelecida a ideia de que as fronteiras impostas pelos europeus desconsiderava por completo os grupos étnicos, cabe pensarmos o que são esses grupos e quais são suas fronteiras. A princípio, o próprio termo "etnia" remete, de alguma forma, ao continente africano, visto que possui má fama na França, atualmente, "precisamente por não poder 
mais ser pensado de outro modo, a não ser como substituto da palavra 'raça", ou então, no caso de estudos ingleses em que a definição do termo "resolve-se antecipadamente pela equivalência ethnicity = foreign stock." (POUTIGNAT; STREIFF-FENART, 20I , p. 23)

Compreende-se, então, que em estudos realizados na Europa, principalmente até os anos de 1960, etnia era termo que substituía pejorativamente ora o termo raça, no caso da França, ora as noçóes de estrangeiro, daquele que náo era anglo-americano, no caso da Inglaterra. Em outras palavras, vemos resquícios de um passado recente e impregnado de teorias racialistas, as mesmas que levaram o europeu a minimizar africanos e asiáticos na Era dos Impérios. (HOBSBAWM, 2015)

Ademais, se continuarmos a olhar para os estudos da etnicidade, perceberemos que a partir do final da década de 1960 e início da de 1970 , novos conceitos e visôes começaram a surgir, provocando mudança de entendimento a respeito de etnia, de modo que deixa de ser tratada como simples sinônimo de raça para algo bem mais complexo, como autodeclaração subjetiva que sinaliza o pertencimento a um determinado grupo imaginado, dotado de mesmo passado histórico e cultural. (POUTIGNAT, STREIFF-FENART, 20II, p. 24-25)

Os debates envolvendo a nova definiçẫo de etnia motivou discussôes sobre as naçóes pluriétnicas, termo que se encaixa no caso dos países africanos. As fronteiras impostas pelos europeus, conforme contrastado anteriormente, formaram um contexto no qual, a partir das independências de tais 'países', quiçá Estados-Nação à moda europeia, vários povos compóem naçóes pluriétnicas ou multiétnicas. Essa situação gerar uma realidade extremamente conflituosa, dado que etnias historicamente inimigas foram obrigadas a conviver sob o mesmo aparato administrativo e econômico e uma delas pode exercer domínio sob a outra com a conquista do aparelho de Estado. Logicamente, todo esse processo acabou por gerar (e ainda gera) um contexto de longas e diversas guerras civis: Tutsis e Hutus, em Ruanda; Igbos e Hauçás, na Nigéria, entre tantas outras outras.

$\mathrm{O}$ caso ficcional de Beasts of no nation pode ser analisado à luz de noçóes contrastantes de grupos étnicos e Estado-nação. Poutignat e StreiffFenart (20II) propóem explicaçóes sobre o que acontece nesses contextos, afirmando haver uma relação: 
[...] entre a visão etnocêntrica dos não africanos, para quem os membros das naçôes africanas são simples tribesmen, e o viés ideológico introduzido pelas elites africanas no poder, que têm tendência a etiquetar como 'nacionalismo' as aspiraçóes aos Estados que elas aprovam ou aos quais aspiram, e a estigmatizar como 'tribalismo' aquelas que visam a formação de Estados que elas desaprovam. (POUTIGNAT; STREIFFFENART, 20II, p. 82)

Ademais, os estudos étnicos, uma vez estabelecidos, refletem diretamente sobre a própria África. Como exemplo, temos Southall (1970 apud POUTIGNAT, STREIFF-FENART, 20II, p. 3i), que ao se referir aos antropólogos ocidentais diz que eles "devem deixar de qualificar de primitivas e de tribais as comunidades contemporâneas de onde originaram-se seus colegas do Terceiro Mundo." Ou seja, os estudos étnicos vão percebendo as várias incongruências do pensamento europeu/ocidental contemporâneo, que ainda traziam consigo muito das teorias racialistas.

Por fim, vale ressaltar o papel da etnicidade em todo esse processo, uma vez que é este o campo de pesquisa que define os principais rumos de estudo das questóes étnicas, como seus grupos e fronteiras. Poutignat e Streiff-Fenart definem etnicidade como:

[...] uma forma de organização social, baseada na atribuição categorial que classifica as pessoas em função de sua origem suposta, que se acha validada na interação social pela ativação de signos culturais socialmente diferenciadores. [...] estudo dos processos variáveis e nunca terminados pelos quais os atores identificam-se e são identificados pelos outros na base de dicotomização Nós/Eles, estabelecida a partir de traços culturais que se supóe derivados de uma origem comum e realçados nas interações raciais. (POUTIGNAT; STREIFF-FENART, 20II, p. I4I)

Ressalta o questionamento: etnias podem dividir uma mesma nação? Segundo esses autores, a resposta é sim! Isso se deve à precedência que os grupos étnicos têm em relação aos Estados-nação. Como apontam os 
autores, "etnia e nação são duas noçóes distintas [...] contudo, elas possuem um elemento em comum, a capacidade de sustentar o senso de uma história e de uma cultura comuns." (POUTIGNAT; STREIFF-FENART, 20II, p. 52) $\mathrm{O}$ fato de etnia e nação compartilharem esse senso comum pode fazer com que grupos étnicos diversos convivam sob mesmo aparato governamental?

Essas noçóes contradizem as tradicionais definiçóes sobre grupos étnicos, uma vez que apontavam o isolamento destes como característica crucial para sua formação. (BARTH, 20I I, p. I88)

É possível imaginar que duas etnias não necessariamente precisam ser inimigas: podem dividir nacionalidade, se a convivência ocorrer de maneira pacífica. Podemos pensar ainda que os termos nação e grupos étnicos estiveram ligados, como apresenta Hobsbawm (2013, p. 3I): "o velho significado da palavra [naçáo] contemplava principalmente a unidade étnica, embora seu uso recente indicasse mais 'a noção de independência e unidade política”. Ocorre que os termos estiveram relacionados, mas se distanciaram por passarem a representar questóes distintas na medida em que se lhes impôs a convivência em um único território demarcado por um único poder estatal.

Alcançamos, então, a discussão de novo tópico, que é justamente o das noçôes e processos de formação das nações. Para isso, partiremos das ideias de Benedict Anderson (I989), que define nação como limitada, soberana e presente em uma comunidade. Ao dizer limitada, ele se refere ao seu caráter fronteiriço, ou seja, ao limite político territorial intrínseco a toda nação. Soberana, pois substitui os reinos dinásticos hierárquicos existentes entre os séculos XV e XVIII, tornando-se essas novas 'naçóes' os principais agentes do poder. E comunitário, por fim, pois, em tese, "a nação é sempre concebida como um companheirismo profundo e horizontal.” (ANDERSON, I989, p. I6)

Mas, para além dessa definição, é necessário ter em mente que o processo de formação de uma nação se dá de cima para baixo, já que é imposto pelas classes dominantes às classes mais baixas. Como aponta Hobsbawm (2013, p.II5-II6), "o Estado dominava sobre um 'povo' territorialmente definido e o fazia como a agência 'nacional' suprema de domínio sobre seu território, e seus agentes cada vez mais alcançavam os habitantes mais humildes do menor de seus vilarejos." A relação 
social em torno do processo de construção da nação é vertical. Essa argumentação se fecha quando Anderson (1989) afirma que a nação vem para substituir a soberania que as dinastias monárquicas haviam deixado vagas a partir do século XVIII, principalmente pós-Revolução Francesa. Essas dinastias também vieram a suprir a falta de referencial que a Igreja católica da Idade Média deixou pós-Reforma Protestante. Segundo Anderson (1989, p. 20), "os dois sistemas culturais relevantes são a comunidade religiosa e o reino dinástico [...] em seu apogeu, eram aceitos como verdadeiros quadros de referência, tanto quanto é, hoje em dia, a nacionalidade.”

Entretanto, há alguns fatores que fazem o caminho inverso no processo de construção nacional, configurando o que se denomina 'protonacionalismo popular'. Ele envolve, principalmente, símbolos, rituais e práticas populares, além do que Hobsbawm vai chamar de "historicidade nacional” (2013, p. 98), e que podemos interpretar como sendo um passado histórico imaginado socialmente por aquela comunidade, para nos valermos das reflexôes de Anderson (1989).

Ademais, há a questão da língua, que comumente é tratada como protonacional. Ocorre que, mesmo partindo de línguas vulgares, a língua da nação está ligada a um "instrumento de centralização administrativa" (ANDERSON, 1989, p. 50) e os efeitos do capitalismo editorial, responsável por gerar "[...] nova fixidez à língua, que, a longo prazo, ajudou a construir aquela imagem de antiguidade, tão essencial à ideia subjetiva de nação." (ANDERSON, I989, p. 54) Isto é, a língua também está associada a esse processo de criação da comunidade imaginada que forma o Estadonação, por parte de um grupo dominante.

Afinal de contas, como todo esse processo de criação de nação pode ser percebido em Beasts of no nation?

A começar pela primeira definição de Anderson (1989), se olharmos para o período do colonialismo, veremos que os três pontos do autor estadunidense não se aplicam à África. As fronteiras do continente, como já discutimos no início do capítulo, são problemáticas até hoje. A questão da soberania no continente foi bruscamente rompida: de um sistema de impérios africanos (lembrando que a noção de império na África é bem distinta da europeia) para um sistema de governo colonial e racialista. 
Por fim, temos a questáo das comunidades, ponto que pode ser discutido pelo viés das etnias. Como comentado anteriormente, a África traz consigo grande quantidade de conflitos étnicos, logo, não há maneiras de se instituir uma comunidade nacional, tal qual apresentado por Anderson e Hobsbawm, indo, inclusive, na contramão deste último, que afirmou: "poucos movimentos nacionalistas modernos são realmente baseados em consciência étnica." (HOBSBAWM, 20I3, p. 89)

Vimos, ainda, que o processo de formaçáo da consciência nacional parte de cima para baixo, com a imposição de características que os próprios governantes queiram, somados a eventuais protonacionalismos. No entanto, a imposição veio do europeu, que desconhecia completamente as culturas locais e que náo tentou, em momento algum, criar sentimento nacional, senáo implantar teorias racialistas que diminuíam os autóctones e impunham a nacionalidade europeia, apresentando um passado histórico e cultural que em nada representava as populaçôes autóctones de África.

\section{Etnia, nação, fronteiras e conflitos em Beasts of no nation}

Para iniciar as reflexóes acerca do filme Beasts of no nation, remetemos à passagem em que há uma reunião da população da cidade em que vive Agu; dois principais grupos inimigos (Conselho de Reforma Nacional e a Força de Defesa Local, respectivamente representados pelas siglas CRN e FDL) estão prestes a chegar à cidade e seus habitantes se encontram na igreja para discutir o que fazer. Nessa passagem, podemos ver um personagem que, muito provavelmente, representa um líder religioso local, por conta: (i) de sua vestimenta, (ii) de sua fala em akan e (iii) do tratamento recebido pela comunidade.

Vemos também, nas paredes do templo, dois quadros com imagens de Jesus Cristo, símbolo religioso do cristianismo. Como sabemos, os missionários católicos foram peça importantíssima na dominação colonial europeia - temos nesta cena um exemplo da imposiçáo cultural exercida pelos europeus sobre os africanos. Contudo, igualmente notamos que houve nesse processo forte mudança de costumes da religiáo 
cristã na assimilação pelos autóctones, daí a manutenção da importância do líder religioso tradicional e a forma como se celebra o culto católico. Exemplificando este último ponto, temos Agu dizendo, durante um culto: "God is liking music more than just talking so if we are singing and dancing, then. He is listening to us well well” " (FUKUNAGA, 20I4, p. 07), uma concepção lúdica e corporal do cristianismo, bem diferente do modelo europeu.

Ainda nessa reunião, em um determinado plano aberto, que foca no interior da igreja, lotada de pessoas, podemos ver um jovem com a camiseta da seleção inglesa de futebol. Esse outro aspecto também reflete, e muito, um embate cultural de caráter nacional, como aponta Hobsbawm (2007, p. 92), ao dizer que "a dialética das relaçóes entre a globalização, a identidade nacional e a xenofobia é enfaticamente demonstrada pela atividade pública que combina esses três elementos: o futebol”. Entende-se, então, a importância do futebol na relação dos três elementos citados pelo autor inglês, mas o ponto ao qual se pode chegar, analiticamente, é de que

[...] o negócio global do futebol é dominado pelo imperialismo de umas poucas empresas capitalistas com nomes de marcas também globais [...] seus jogadores são recrutados em todo o mundo. Com frequência apenas uma minoria [...] dos jogadores tem a nacionalidade do país onde se situa o clube. A partir da década de 1980, eles provêm cada vez mais de países nãoeuropeus, especialmente da África, que tinha cerca de 3 mil jogadores atuando nas ligas europeias em 2002. (HOBSBAWM, 2007, p. 93)

O imperialismo de empresas internacionais, juntamente com a desestruturação nacional dos países africanos, constrói situaçóes sociais como a que é apresentada na cena supracitada. Nela, um jovem leva consigo uma camisa de outra seleçáo nacional, talvez daquela em que ele gostaria de jogar, uma vez que é difícil pensar em organizar uma seleção de futebol com um país em guerra civil, como o do filme. Hobsbawm (2007) não deixa de fazer uma reflexão sobre a indústria do futebol ser responsável por situar os superclubes acima das seleçóes e interroga se esses casos 
não marcariam uma decadência da noção de nação no alvorecer do século XXI. Entretanto, o historiador inglês faz uma ressalva quanto à indústria de futebol e a África, ao apontar que:

[...] para muitos países africanos e para alguns dos países asiáticos cujos jogadores se tornaram famosos (e ricos) na economia dos grandes clubes, a existência da seleção nacional de futebol se estabeleceu, em alguns casos pela primeira vez, uma identidade nacional independente das identidades locais, tribais ou religiosas. (HOBSBAWM, 2007, p. 94-95)

Essa questão fica mais perceptível quando vemos que a primeira edição da Copa Africana de Naçóes, em I957, contou com apenas 3 participantes (Egito, Etiópia e Sudão), e que, na edição de 20I7, foram 5 I países inscritos e I6 participantes. Desse modo, percebemos a importância desse esporte nas questôes de nacionalidade no continente africano.

Beasts of no nation ainda reforça como o futebol está presente nesse contexto em outras duas passagens, para além daquela camisa de seleção. Na primeira, que compóe a cena inicial do filme, vemos algumas crianças jogando bola, por entre as telas da "TV da imaginaçáa", como os próprios garotos a apelidam, ao invés de estarem em sala de aula, o que ocorre como consequência da guerra; já na segunda, temos alguns integrantes do FDL jogando, enquanto outros assistem, inclusive o personagem Comandante, que ri quando irrompe briga entre os jogadores, por conta de discussão envolvendo a marcação de gol.

Por fim, podemos perceber como a nacionalidade do país sem nome é trabalhada. Fukunaga (2014) nos apresenta, em determinado momento do primeiro ato, quando Agu e seu irmão se despedem de sua mãe, por conta da chegada do conflito ao seu vilarejo, um take mais demorado que o comum, visando proporcionar ao espectador a oportunidade de visualizar uma pintura na parede do vilarejo, que traz os seguintes dizeres: "Fight no more - Cooperation builds our nation" ${ }^{2}$. Essas frases seriam condizentes com a realidade do filme, náo fosse o desenho de pessoas brancas apresentadas como construtoras da naçáo, pois isso o dota de falta de representatividade da população autóctone e ainda reflete os efeitos da colonização europeia. 
Ademais, abordamos a guerra associado ao aspecto étnico, por conta de frases que surgem em faixas e pichaçôes, como "It's our turn to eat" ${ }^{3}$, que é apresentada mais de uma vez no decorrer da narrativa. Esse tipo de afirmação costuma se dar, historicamente, em contextos de guerras civis ocasionadas por conflitos étnicos em que há a tomada de poder pelo grupo que sofria abusos de outro. Entretanto, o filme não deixa claro a motivação, já que contamos, ao menos, três grupos conflituosos. Podemos interpretar essa não definiçáo como uma forma de ressaltar que os conflitos ocorridos no continente são ocasionados por diversos fatores, referidos a uma complexa e diversificada realidade das 'Áfricas'.

Por fim, podemos afirmar que as realidades africanas são completamente capazes de estabelecer Estados-nação ou qualquer outra forma de governo, mas as sucessivas incursóes brutais por parte da Europa, dos Estados Unidos e, mais recentemente, da China, com seus respectivos agentes externos, fazem com que o processo nunca se dê naturalmente. Impóe-se uma língua, um sistema administrativo e econômico, uma religião, uma cultura. Continuam a ocorrer interferências no continente, de tal maneira que a autoconstrução dos países é constantemente boicotada.

O protonacionalismo (associados às culturas étnicas) e a ideia nacionalista (que é construída de cima para baixo, como apresentado por Hobsbawm) também são insistentemente solapadas, pois não há continuidade de governos, além de conflitos ocasionados por interesses econômicos, motivados por agentes externos, e étnico-raciais, por parte da população forçosamente agrupada.

Mas, tal qual Agu, a África ainda tem uma identidade, um passado histórico que está sendo retomado por meio de estudiosos e da população, como aponta Weber (2012, p. 06) na primeira metade de seu texto, ao afirmar que:

[...] na atualidade, com o advento das mídias apropriadas para digitalização e, para o pesquisador impossibilitado de realizar uma viagem para coleta de materiais, há uma série de arquivos que estão à disposição dos pesquisadores através de sites especializados. 
Assim, os avanços da historiografia africana nos ajudam, hoje, a olhar todo o processo de colonização sob outra perspectiva. Tem-se que concordar com Weber (2012, p. 07) quando diz que "cada obra lida era um mundo novo construído aos nossos olhos, cada fonte revelava outra sociedade, muito diferente de todos os modelos ocidentais." É a África se revelando para nós, dessa vez com voz própria. Desse modo, quando o menino Agu, principal personagem de Beasts of no nation e metáfora do continente africano, mergulha no mar, na última cena, revela a representação de um futuro otimista, apesar do passado dolorido e do presente incerto.

\section{Consideraçóes finais}

Levar adiante a construção de práticas educativas que tenham como proposta o pensamento decolonial e a interculturalidade no Brasil envolve, especialmente, o enfrentamento das consequências geradas pela escravidão africana, tanto do ponto de vista material quanto simbólico.

Para tanto, torna-se urgente pensar na educação para as relaçôes étnico-raciais, o que implica, entre outras coisas, refletir sobre a História e Cultura Africanas, posto que países desse continente ora são desconhecidos, ora são conhecidos de modo estereotipado, dada a associação ao atraso e a barbárie. E a escola é a instituição de suma importância para a promoção desse pensamento decolonial e da interculturalidade no Brasil, em razão do alcance social que possui, cabendo pensar, no entanto, na maneira de promover essa ação. A sugestão aqui apresentada envolve a apropriaçáo pedagógica de discursos cinematográficos. Ao elaborar propostas de educação para as relaçóes étnico-raciais com base em filmes deve-se atentar para a existência de um conjunto de obras marcadas fortemente pelo olhar ocidental sobre o Oriente, o que exige pensar em alternativas mais críticas e problematizadoras da realidade africana.

Tal postura envolve, principalmente, refletir sobre conceitos como etnia, nação e fronteiras, pois oportunizam entendimento mais agudo dos conflitos sociais que explicam, em boa medida, as dificuldades vividas por esses povos, bem como uma compreensão mais dilatada da riqueza cultural que comportam. 
Nesse sentido, acompanhar a trajetória do menino Agu em Beasts of no nation é oportunidade interessante para tratar, num país que apresenta a segunda maior populaçáo negra do mundo e é fortemente tributário das culturas africanas, da dívida social inquestionável com os afro-brasileiros.

\section{Notas}

Texto derivado do Projeto "Refletindo sobre a África contemporânea e a educação das relaçôes étnico-raciais: a propósito da apropriação pedagógica do filme Bests of no nation", financiado pelo CNPq.

I "Deus prefere música a só conversa. Então, se estiver cantando e dançando, ele estará ouvindo atentamente."

2 "Lutas/Guerras nunca mais" e "A cooperação constrói nossa nação".

3 "É nossa vez de comer".

\section{Referências}

ALEGRIA, José; DUARTE, Rosália. Formação estética audiovisual: um outro olhar para o cinema a partir a educação. Educação \& Realidade, Porto Alegre, v. 33, n. I, p. 59-80, jan./jun. 2008.

ALVES-MAZZOTTI, Alda Judith; GEWANDSZNAJDER, Fernando. O método nas ciências naturais e sociais. São Paulo: Pioneira, I999.

ANDERSON, Benedict. Nação e consciência nacional. São Paulo: Ática, I989.

ARMES, Roy. O cinema africano ao norte e ao sul do Saara. In: MELEIRO, A. (Org.). Cinema no mundo: indústria, política e mercado - África. São Paulo: Escrituras, 2007, p.I43-189.

BALOGUN, Françoise. A explosão da videoeconomia: o caso da Nigéria. In: MELEIRO, A. (Org.). Cinema no mundo: indústria, política e mercado - África. São Paulo: Escrituras, 2007, p.I9I-204.

BARTH, Fredrik. Grupos étnicos e suas fronteiras. In: POUTIGNAT, Philippe; STREIFF-FENART, Jocelyne. Teorias da etnicidade: seguido de grupos étnicos e suas fronteiras de Fredrik Barth. São Paulo: Editora UNESP, 20I I. p.I87-227.

BEASTS OF NO NATION. Dir.: Cary Joji Fukunaga. Estados Unidos: 2015 (I37 min). BELLONI, Maria Luiza; BÉVORT, Evelyne. Mídia-educação: conceitos, história e perspectivas. Educação \& Sociedade, Campinas, v. 30, n. I09, p. I08I-I IO2, set./dez. 2009. 
BRASIL. Lei 13.006, de 26 de junho de 20I4. Brasília, 2014.

BRASIL. Ministério da Educação. Conselho Nacional de Educação. Diretrizes Curriculares Nacionais para a Educação das Relaçôes Étnico-Raciais e para o Ensino de História e Cultura Afro-Brasileira e Africana. Brasília: Portal do MEC, 2004.

CABRERA, José. O cinema pensa: uma introdução à filosofia através dos filmes. Rio de Janeiro: Rocco, 2006.

FREIRE, Paulo. Pedagogia da autonomia: saberes necessários à prática educativa. Rio de Janeiro: Paz e Terra, 2016.

FRESQUET, Adriana. (Org.). Cinema e educação: a lei I3.006 - reflexóes, perspectivas e propostas. Belo Horizonte: Universo Produção, 2015.

FUKUNAGA, Cary Joji. Beasts of no nation. Shooting script, 2014.

GAMBOA, Silvio Sánchez. (Org). Pesquisa educacional. São Paulo: Cortez, I997.

GIL, Antonio Carlos. Métodos e técnicas de pesquisa social. São Paulo: Atlas, I994. . Como elaborar projetos de pesquisa. São Paulo: Atlas, 2007.

HOBSBAWM, Eric. A era dos impérios, 1875-1914. São Paulo: Paz e Terra, 2015. . Globalização, democracia e terrorismo. São Paulo: Companhia das Letras, 2007. . Naçóes e nacionalismo desde 1780: programa, mito e realidade. São Paulo: Paz e Terra, 20I3.

HOUAISS. Dicionário eletrônico Houaiss da língua portuguesa. Rio de Janeiro: Objetiva, 2009. I CD ROM.

MINAYO, Maria Cecilia de Souza. (Org). Pesquisa social. Petrópolis: Vozes, 2000. NAPOLITANO, Marcos. Como usar o cinema na sala de aula. São Paulo: Contexto, 2008.

PERINELLI NETO, Humberto. (Org.). Ver, fazer e viver cinema - experiências envolvendo curso de extensão universitária. São Paulo: Cultura Acadêmica/PROEXUNESP, 2016.

POUTIGNAT, Philippe; STREIFF-FENART, Jocelyne. Teorias da etnicidade: seguido de grupos étnicos e suas fronteiras de Fredrik Barth. São Paulo: Editora UNESP, 20 I I. SAID, Eduard Wadie. Orientalismo: o Oriente como invenção do Ocidente. São Paulo: Companhia das Letras, 2007. 
SENGER, Guilherme Felkl. História da África contemporânea e Cinema: estudo das representaçóes dos filmes "O Último Rei da Escócia”, "Diamante de Sangue" e "O Jardineiro Fiel”. Aedos, Rio Grande do Sul, v. 4, n. II, p. 524-548, 2012.

SETTON, Maria das Graças. Educação e mídia: um diálogo para educadores. São Paulo: Editora Contexto, 2010.

TRIVINŌS, Augusto Nibaldo Silva. Introdução à pesquisa em ciências sociais. São Paulo: Atlas, I987.

UECHI, Gabi. Nollywood: A explosão do cinema nigeriano. Disponível em: <http:// www.afreaka.com.br/notas/nollywood-a-explosao-do-cinema-nigeriano/>. Acesso em: I5 mar. 2017.

WEBER, Priscila Maria. Africanidades em questão: o desenvolvimento dos estudos africanos e alguns apontamentos sobre a ascensão da rainha Nzinga Mbandi ao poder no Ndongo e Matamba. Contemporâneos, n. IO, p. I-22, maio/out. 2012.

Recebido em I9 fev. 2018 / Aprovado em 20 mar. 2018

Para referenciar este texto

PERINELLI NETO, H; BALDACIN JUNIOR, A. C. Pensar a África em sala de aula: ensino, conhecimento logopático e africanidades no filme Beasts of no nation. EccoS - Revista Científica, São Paulo, n. 45, p. 79-Ioo. jan./abr. 2018. Disponível em: $<$ https://doi.org/I0.5585/EccoS.n45.8369>. 